\title{
Analisa Kerusakan Relay Valve Dan Air Dryer Pada Air Charging System Unit Heavy Equipment Off Highway Truck (OHT) 777D Caterpillar
}

\author{
Mangkona $^{1 *}$, Baso Cante ${ }^{2}$, Hasan Basri $^{3}$, Adriansyah $^{4}$ \\ ${ }^{123}$ Jurusan Teknik Mesin, Politeknik Negeri Samarinda, Kalimantan Timur, 75131, Indonesia \\ ${ }^{4}$ Jurusan Teknik Mesin, Politeknik Negeri Padang, Sumatera Selatan, 25163, Indonesia
}

\begin{abstract}
Article Info ABSTRAK

\begin{tabular}{|c|c|}
\hline & $\begin{array}{l}\text { dara merupakan media penerus tenaga pada Air System Of Highway Truck 777D Caterpillar. } \\
\text { dara dimanfaatkan untuk menjadi suplai pada sistem pengereman pada Of Highway Truck 777D }\end{array}$ \\
\hline Received : & ik untuk proses teknis \\
\hline Pebruary $27^{\text {th }}, 2020$ & f Highway Truck 777D Caterpillar dan kerusakan apa yang sering terjadi, serta bagaimana cara \\
\hline Revised & ada Of Highway \\
\hline May $10^{\text {th }}, 2020$ & $\begin{array}{l}\text { Truck 777D Caterpillar. Metode yang digunakan dalam penelitian ini adalah observasi lapangan, } \\
\text { library research, melakukan, inspeksi dengan beberapa unit yang mengalami schedule dan }\end{array}$ \\
\hline Acc & cheduled perbaikan. Menurut literatur yang sesuai, kerusakan komp \\
\hline May $28^{\text {th }}, 2020$ & $\begin{array}{l}\text { lan keausan pada komponen. Penelitian dilal } \\
\text { lal dan pengukuran, kemudian dilakukan an } \\
\text { Hasil penelitian ini menemukan adanya keru }\end{array}$ \\
\hline & Iryer pada air charging system. \\
\hline
\end{tabular}
\end{abstract}

Kata kunci: Air charging system, Relay valve, Air Dryer, Off High Truck, Caterpillar

\begin{abstract}
ABSTRAK
Air is the successor to the Caterpillar 777D Highway Truck Air System. Air is used to supply the braking system on the Caterpillar 777D Highway Truck which is then collaborated with a hydraulic system for the technical braking process. For this reason, the authors analyze the components of the 777D Caterpillar Highway Truck Air System and what damage often occurs and how to repair it. In this case the object examined is the water system component of the Caterpillar 777D Highway Truck. The method used in this research is field observation, literature study, conducting, inspection with several units that improve the schedule and scheduled repairs. According to the appropriate literature, component damage that occurs in air systems is damage to the system and wear and tear on components. The study was conducted by conducting a visual inspection and measurement, then an analysis of the assessment of the appropriate data literature was carried out. The results found damage to the maintenance component that is not really a component relay valve and air dryer on the air filling system.
\end{abstract}

Keywords: Air charging system, Relay valve, Air Dryer, Off High Truck, Caterpillar

Corresponding Author:

Mangkona

Department of Mechanical Engineering

Politeknik Negeri Samarinda,

Jl, Ciptomangunkusumo Kampus Gunung Lipan, Samarinda 75131, Indonesia

Email: mangkona_a@yahoo.com 


\section{PENDAHULUAN}

Salah satu alat berat yang memiliki fungsi sebagai pemindah material adalah Of Highway Truck atau yang biasa disebut OHT. OHT adalah unit yang efektif dalam hal memindahkan material karena mempunyai banyak keunggulan seperti dalam hal banyaknya muatan, ketangguhan dalam medan tambang yang berlumpur, berbatu, dan berbukit. Durasi kerja OHT yang berkelanjutan pasti akan membuat kerusakan yang tidak diinginkan dan terjadi kegagalan pada salah satu sistem, salah satunya adalah kesalahan pada Air System (Sistem udara). Air System pada OHT digunakan untuk banyak hal, seperti sistem pengereman, air horn, sumber tenaga untuk supply Autolube, dan alat pembersih. Oleh karena itu, menjaga agar Air System selalu siap digunakan adalah salah satu hal yang penting untuk menjaga produktivitas.

Perusahaan kontraktor yang bekerja di bidang pertambangan memiliki banyak unit yang beroperasi untuk mendukung operational produksi, dibutuhkan unit yang beroperasi untuk kegiatan pengangkutan material tanah dan batu bara seperti OHT 777D. Salah satu sistem penting yang terdapat pada OHT 777D adalah air system. Permasalahan air system yang sering dialami pada unit OHT 777D yaitu terjadinya kerusakan pada air systemnya seperti air pressure drop, kebocoran pada komponen, dan beberapa komponen tidak bekerja sesuai dengan fungsinya dikarenakan kerusakan pada komponen air system sehingga unit tidak dapat dioperasikan jika terdapat masalah pada air system. Data kerusakan air system dapat diperoleh melalui WO (Work Order) dan DMBD (Daily Mean Breakdown). Pada analisa data daily mean breakdown menunjukkan jumlah terjadinya permasalahan pada air system pada unit OHT 777D di PT. Arkananta Apta Pratista yang terjadi di site 017C Malinau terhitung mulai Januari 2019 - Juni 2019. Dari data tersebut diperoleh data kerusakan pada 6 bulan terakhir yaitu 19 kerusakan, dan rata - rata kerusakan harian dalam 6 bulan terakhir salah satunya adalah pada air system [1].

Angka kerusakan yang tinggi itulah maka penulis mengangkat permasalahan ini dengan judul penelitian Analisa Kerusakan Air System pada Unit Of Highway Truck (OHT) 777D Studi Kasus PT. Arkananta" untuk memberikan solusi pada PT. Arkananta Apta Pratista untuk mengatasi permasalahan tersebut. Adapun tujuan penelitian yang ingin dicapai dalam penelitian ini adalah mengidentifikasi penyebab kerusakan pada komponen air charging system 777D. Penelitian terkait menjelaskan faktor-faktor struktural terpilih yang mempengaruhi operasi relay valve dan yang penting untuk memastikan keselamatan lalu lintas kereta. Faktor-faktor tersebut adalah pelumas yang digunakan dalam relay valve dan cara mengendalikannya secara bersamaan dengan dua sinyal dengan fungsi alternatif yang menghilangkan elemen yang tidak dapat diandalkan dari sistem pengereman [2]. Transportasi tujuannya adalah untuk memastikan keselamatan operasional dengan mempertahankan yang tertinggi kualitas, efisiensi dan keandalan sistem pengereman [3][4]. Hasil dari penelitian [5] menunjukkan bahwa penyebab service brake malfunction pada unit dump truck HD 1500-7 adalah pressure switch yang tidak mengirim signal ke retard control monitor, dikarenakan micro switch yang rusak disebabkan tombol micro switch yang tidak berfungsi karena benturan piston pressure switch secara terus menurus oliakan masuk ke dalam pressure switch karena lama penggunaannya. Berdasarkan hasil analisa kerusakan pada braking system tersebut di dapatkan kerusakan pada sambuan house dengan kaliper yang bocor, piston brake yang berkarat, o-ring yang sudah sobek/putus, pads brake yang sudah tak layak pakai [6].

\section{Kajian Teoritis}

Sistem pengisian udara pada unit adalah suatu sistem yang terdiri dari beberapa komponen yang berfungsi untuk brake system (sistem pengereman). Selain untuk sistem pengereman, air charging system juga berfungsi untuk klakson (horn), kursi operator (air seat) dan penggerak pompa autolube. Sistem pengisian udara menyiapkan udara standby yang siap digunakan ketika operator ingin menggunakan pengereman, klason atau mengatur kursi operator. [7]

\section{Skematik Pengisian Udara (Air Charging Schematic)}

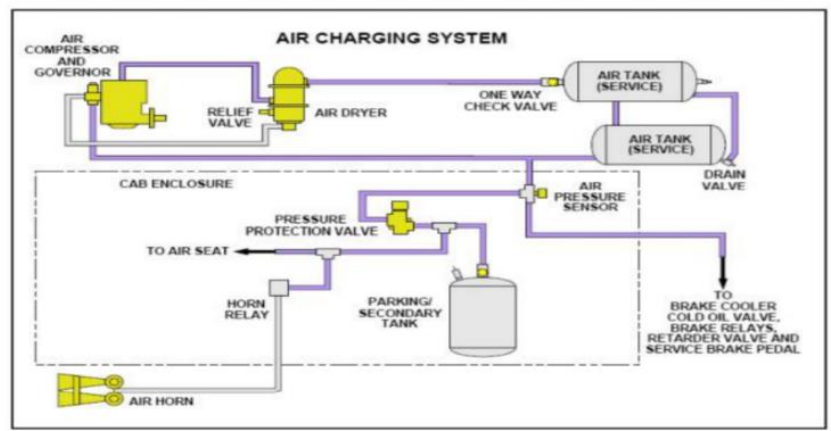

Gambar 1. Skematik Pengisian Udara Pada OHT 777D Caterpillar 
Skematik di atas menunjukkan aliran udara pada air charging system. Udara mengalir dari air compressor, melalui air dryer, menuju service dan retarder brake tank. Udara dari service dan retarder brake tank masuk ke pressure protection valve. Saat tekanan pada service retarder tank mencapai $550 \mathrm{kPa}$ (80 psi), pressure protection valve akan mengalirkan udara menuju parking dan secondary brake tank dan accessory circuit (klakson dan kursi operator). Semua tangki memiliki check valve pada air supply port untuk mencegah hilangnya udara jika terjadi kebocoran pada daerah upstream dari tangki. Air system pressure sensor mengirimkan signal input ke Caterpillar Monitoring System, yang akan menginformasikan ke operator jika tekanan air system rendah.

Air system pressure sensor mengirimkan signal input ke Caterpillar Monitoring System, yang akan menginformasikan ke operator jika tekanan air system rendah

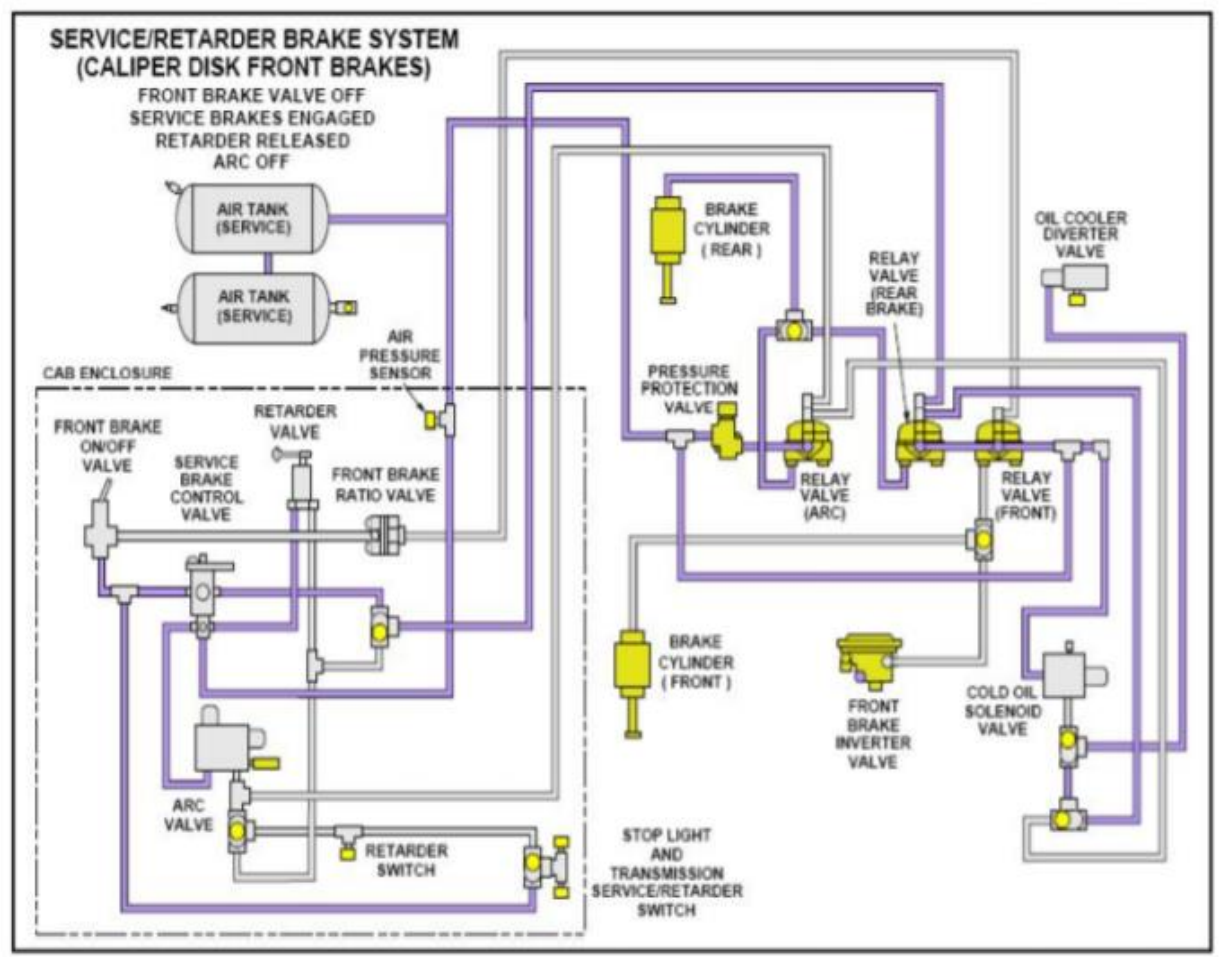

Gambar 2. Skematik Service/ Retarder System Pada OHT 777D

Skematik diatas, menunjukkan aliran udara melalui service dan retarder brake air system pada truck yang dilengkapi dengan caliper disk front brake. Pada skematik ini, front brake ON/OFF valve pada posisi OFF dan service brake control valve ENGAGE. Retarder valve pada posisi RELEASE dan ARC sedang OFF. Udara bertekanan mengalir dari service brake air tank menuju relay valve, cold oil solenoid valve dan melalui air system pressure sensor menuju service brake valve. Udara dari service brake valve mengalir ke retarder valve dan ARC valve [8].

Komponen Air Charging System Adapun komponen - komponen air charging sytem, adalah : Air Compressor, Air Dryer, Air Tank, Relay Valve, Brake Cylinder (Front and Rear) [9].

Tabel 1. Komponen air charging system

\begin{tabular}{|l|l|} 
Air Compressor \& Air Compressor Governor \\
Gambar memperlihatkan gambar belahan dari air compressor \\
governor saat siklus CHARGING (cut-in). Saat piston bergerak turun, \\
kevakuman pada cylinder menyebabkan inlet valve membuka dan \\
udara dihisap kedalam cylinder. Saat piston bergerak naik, tekanan \\
udara dan spring menjaga agar inlet valve untuk piston tersebut \\
menutup. Begitu piston bergerak turu lagi, tekanan pada outlet port \\
dan spring akan membut outlet valve menutup
\end{tabular}




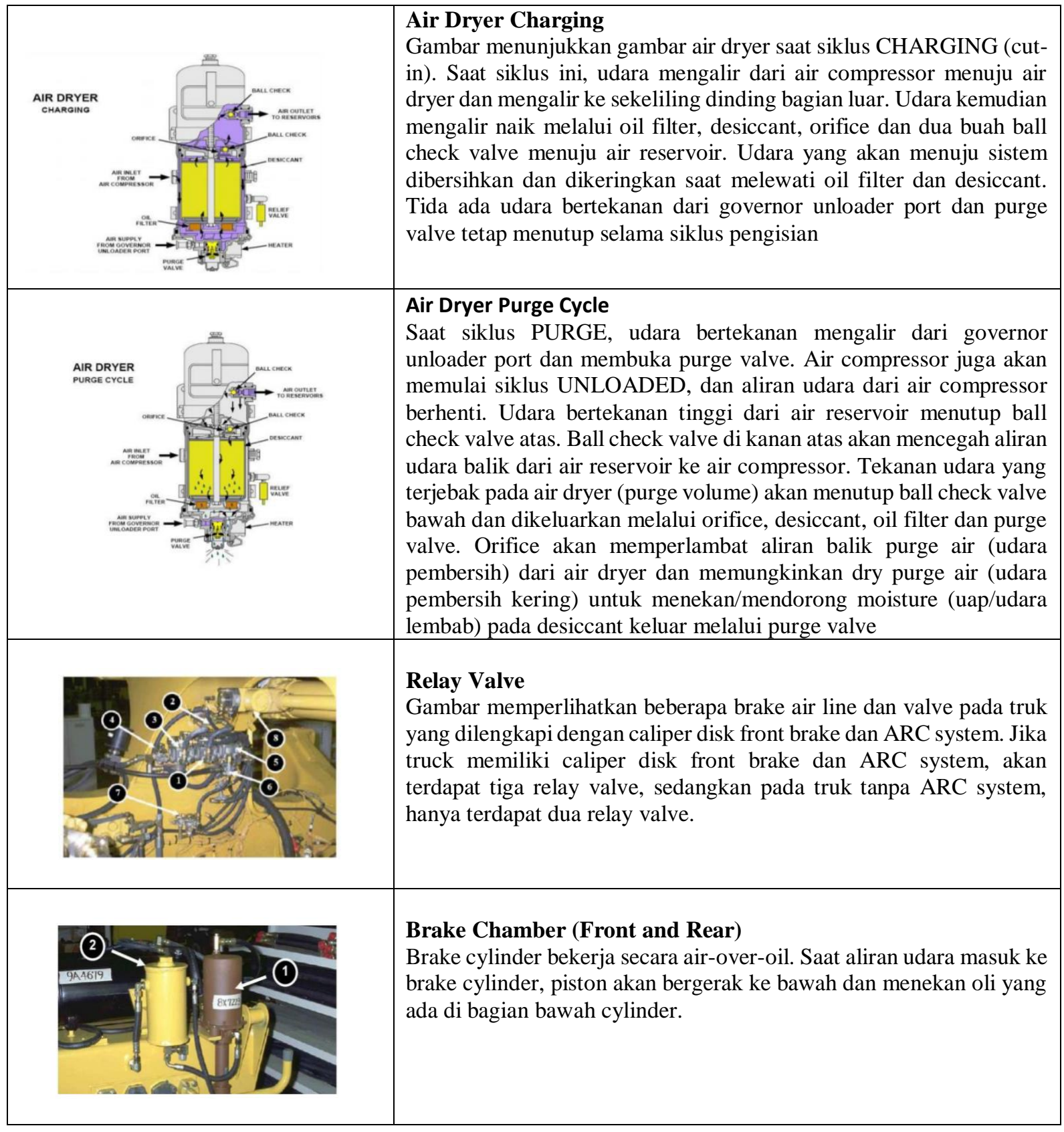

\section{METODOLOGI}

Jenis penelitian yang digunakan oleh penulis adalah studi kasus. Studi kasus adalah penggalian secara mendalam sistem berita contohnya acara aktivitas proses atau individu yang sesuai didasarkan pada pengoleksian data yang cakupannya luas. Studi kasus meliputi investigasi kasus yang bias diartikan sebagai sebuah intensitas maupun objek studi yang dipisah dan terbatas dalam perihal tempat waktu maupun batas-batas fisik. Sangat penting untuk dimengerti bahwasanya kasus bisa berbentuk program individu sekolah kegiatan ruang kelas maupun kelompok. Sesudah kasus dimaknai secara jelas maka peneliti melakukan penyelidikan dengan mendalam pada umumnya memakai sejumlah metode pengumpulan data misalnya observasi lapangan wawancara dan dokumentasi.

Metode penelitian yang digunakan oleh penulis dalam meneliti studi kasus adalah pengamatan visual. Pengamatan visual adalah penggalian dengan cara melihat secara langsung objek yang diteliti secara fisik maupun secara visual. Penelitian dilaksanakan selama fase Apprentice Arka di workshop PT. Arkananta Apta Pratista Site 017C Malinau. Komponen air system yang digunakan untuk pengambilan data penelitian ini adalah Of highway Truck 777D Caterpillar. Dalam penulisan ini objek yang akan dikaji lebih dalam adalah relay valve dan air dryer. 


\section{Prosedur Kerja Penelitian}

Dalam melaksanakan penelitian penulis melakukan riset terhadap permasalahan yang sering muncul pada site 017C Arka Malinau, khususnya fenomena pressure air drop pada unit Of highway Truck 777D. Penulis berkonsultasi dengan pembimbing lapangan dan technical trainer dalam menganalisa penyebab kegagalan pada sistem udara dan melakukan analisa mengapa hal itu dapat terjadi serta cara penanggulangannya.

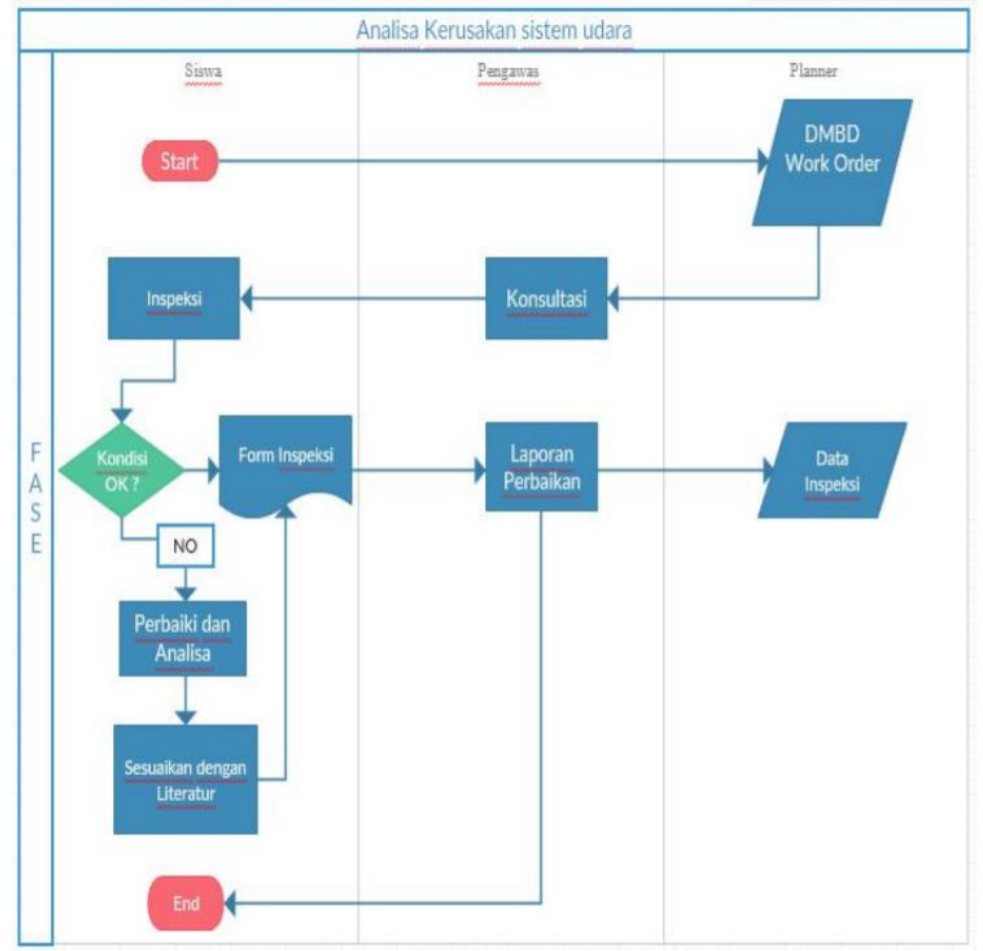

Gambar 3. Analisa kerusakan system udara

\section{Metode Pengumpulan Data}

Metode pengumpulan data yang digunakan dalam penelitian ini adalah observasi diartikan sebagai pengamatan dan pencatatan secara sistematis terhadap gejala yang tampak pada objek penelitian yaitu dengan turun ke lapangan untuk mengamati secara langsung masalah yang terjadi. Melihat kondisi unit, permasalahan, dan lingkungan sekitar area operasi guna mendapatkan informasi, serta untuk menyelesaikan masalah yang sedang terjadi. Datadata yang bisa didapatkan dari kegiatan observasi dalam penelitian ini adalah : data mengenai informasi unit, seperti code unit, serial number unit, hours meter unit, location, environment, dan lain-lain. Data mengenai komponen, seperti keadaan fisik komponen air system, sistem-sistem pada unit, dan lain-lain. Untuk pengumpulan data dengan mencari referensi dalam buku yang relevan, dalam penelitian ini menggunakan Service Information System (SIS), juga literature dan Jurnal ilmiah yang berhubungan dengan pembahasan tersebut. Adapun spesifikasi setiap komponen pada air charging system tersebut adalah:

Tabel 2. Spesifikasi Komponen Air Charging System [10]

\begin{tabular}{|l|l|}
\hline \multicolumn{1}{|c|}{ Nama Komponen } & \multicolumn{1}{|c|}{ Spesifikasi } \\
\hline Charging Air System Specification & $95 \mathrm{Psi}-120 \mathrm{Psi}(660 \mathrm{KPa}-830 \mathrm{KPa})$. \\
\hline Air Compressor Governor & $95 \mathrm{Psi}-120 \mathrm{Psi}(660 \mathrm{KPa}-830 \mathrm{KPa})$ \\
\hline Air Pressure Regulator & $70 \mathrm{KPa}(10 \mathrm{Psi})$ \\
\hline Air Dryer & $120 \mathrm{Psi}(830 \mathrm{KPa})$ \\
\hline Air System Safety Valve & $1380 \mathrm{KPa}(200 \mathrm{Psi})$. \\
\hline Air System Relief Valve & $1034 \pm 55 \mathrm{KPa}(150 \pm 8$ Psi) \\
\hline Pressure Protection Valve & $482 \mathrm{KPa}(70 \mathrm{Psi})$ \\
\hline
\end{tabular}




\section{Metode Pengolahan dan Analisa Data}

Pengambilan Data DMBD (daily mean breakdown) dan work order dianalisa menggunakan microsoft excel, dengan begitu dapat terlihat seberapa sering, seberapa lama, lost time unit tidak beroperasi di karenakan kegagalan pada sistem udara. Dari hasil analisa dapat juga diketahui trending dari tingginya kerusakan komponen sistem udara.

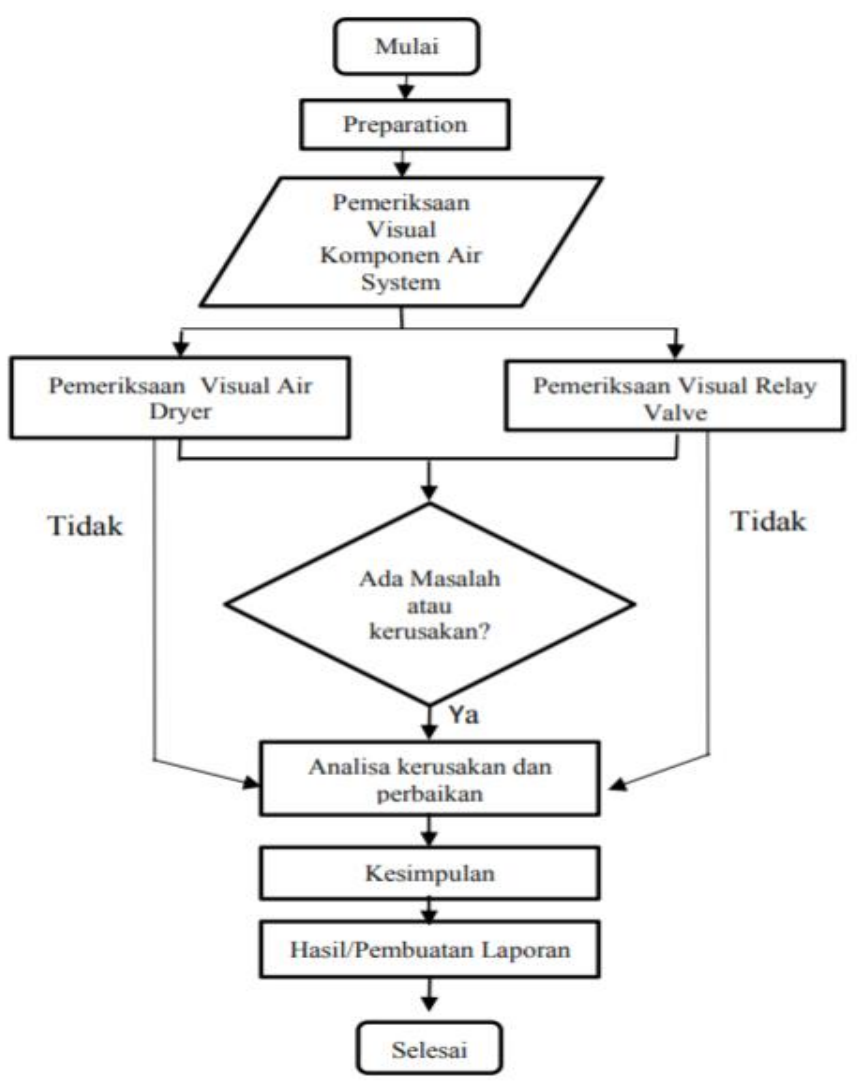

Gambar 4. Diagram alir penelitian

\section{HASIL DAN PEMBAHASAN}

Analisa data work order pada Gambar 5 grafik di bawah menunjukkan jumlah pekerjaan unscheduled (tidak direncanakan) pada unit OHT 777D mengenai problem air system terhitung mulai 1 Juni 2018 - 12 April 2019.

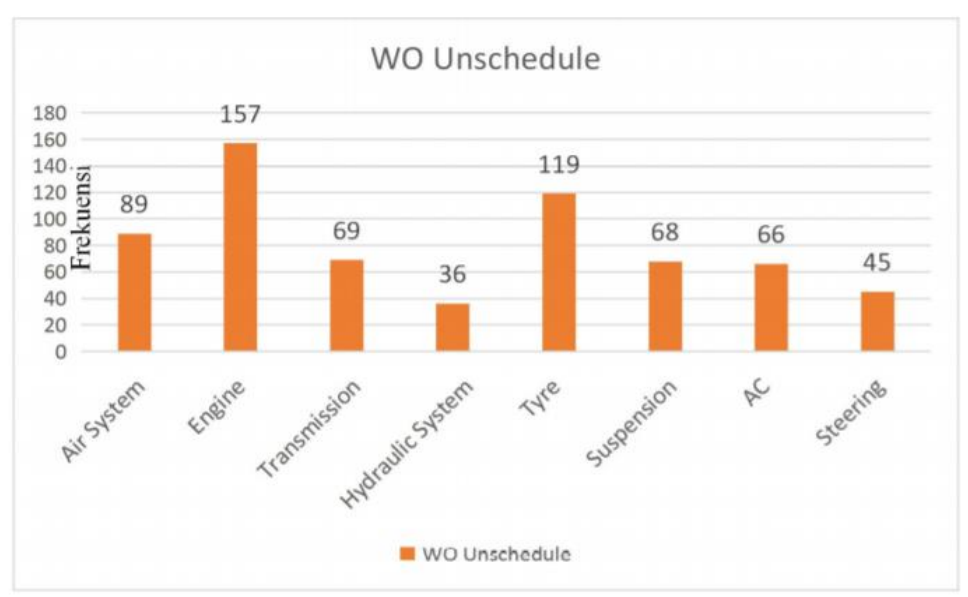

Gambar 5. Jumlah pekerjaan unscheduled pada unit OHT 777D 


\section{Analisa Jenis Kerusakan} lain:

Beberapa jenis kerusakan yang ditemukan pada komponen air dryer dan relay valve, kerusakan itu antara

\section{Air Dryer}

Air dyer adalah suatu komponen yang berfungi sebagai pemisah anatara udara dengan air. Di dalam air dryer sendiri terdapat catriadge yang berfungsi untuk memisahkan udara dan air. Udara dan air harus di pisah karena air tidak 56 boleh masuk kedalam sistem. Karena dapat mengakibatkan kerusakan atau dapat memperpendek usia komponen itu sendiri. Catriadge sendiri seharusnya di cek setiap melakukan PM 250 jam, dan diganti setiap melakukan PM 2000 jam. Berikut adalah contoh kerusakan pada air dryer.

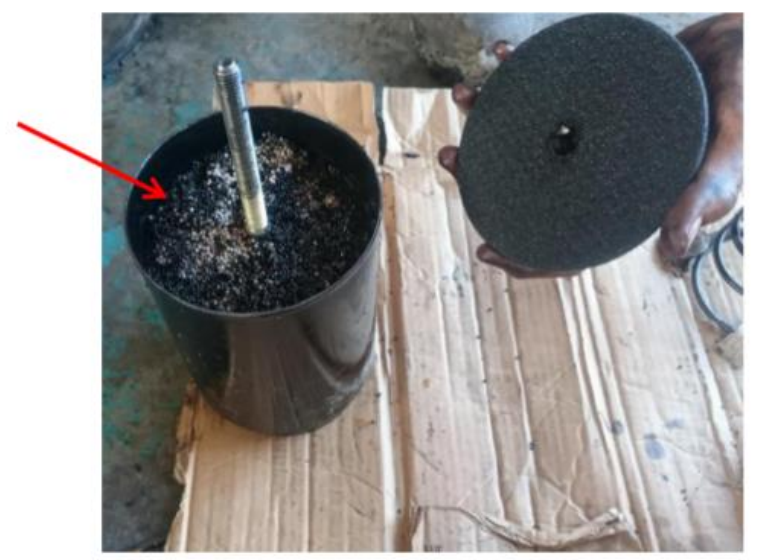

Gambar 6. Jumlah pekerjaan unscheduled pada unit OHT 777D

\section{Relay Valve}

Relay valve adalah salah satu komponen air charging system yang berfungsi untuk membuka jalur angin bertekanan besar dengan memanfaatkan angin bertekanan sedang. Angin bertekanan besar berfungsi sebagai pendorong piston yang ada di dalam brake chamber. Piston yang ada di dalam brake chamber mendorong oli untuk di teruskan ke brake system. Pada studi kasus di PT. Arkananta Apta Pratista saya mendapatkan kasus kebocoran pada relay valve. Kebocoran itu sendiri di akibatkan karena lifetime o-ring pada bagian exhaust passage sudah mencapai waktunya. Dilihat dari ciri-cirinya yang sudah tidak lentur lagi (keras) dan tidak rapat lagi. Ciri-ciri tersebut sama dengan ciri-ciri pada kerusakan jenis fatigue.

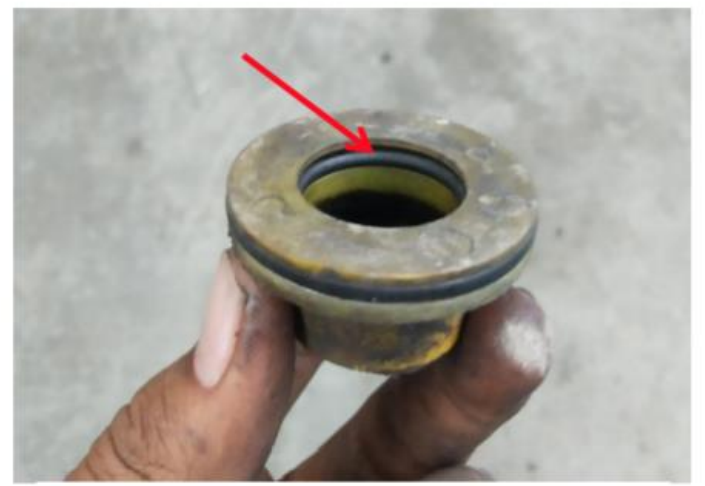

Gambar 7. Jumlah pekerjaan unscheduled pada unit OHT 777D

Cara agar unit tidak breakdown dalam waktu yang lama adalah dengan menyiapkan spare komponen. Jadi ketika terjadi kerusakan pada relay valve pada saat unit beroperasi bisa langsung di ganti atau di tukar dengan komponen yang bagus. Jadi kemungkinan unit breakdown dalam waktu yang lama tidak akan terjadi. 
Kasus kerusakan pada komponen air system pada unit OHT 777D yang terjadi di PT. Arkananta Apta Pratista. Setelah dilakukan pemeriksaan secara visual dan wawancara terhadap mekanik di lapangan, didapat hasil analisa sebagai berikut :

1) Kontaminasi pada relay valve menyebabkan seal pada piston relay valve mengalami kebocoran dikarenakan kontaminasi ikut tertekan bersama udara sehingga seal yang terdapat pada piston relay valve mengalami kerusakan.

2) Oli dan air yang berlebih dari air dryer menyebabkan air dryer bekerja kurang maksimal dikarenakan saringan dari air dryer (catridge) sudah tidak mampu lagi menyekat moisture (uap air) sehingga mengakibatkan uap air tersebut masuk ke sistem (tanki udara dan relay valve).

3) Kebocoran pada komponen relay valve (seal piston dan seal exhaust passage) disebabkan oleh uap air yang ikut tertekan dikarenakan telah terjadi kondensasi pada sistem.

4) Seal yang terdapat pada relay valve mengalami kerusakan jenis fatigue. Karena umur (life time) seal yang sudah melampaui batas pemakaian. Lifetime mengakbatkan seal menjadi keras, selain karena lifetime, kontaminasi juga mempengaruhi seal tersebut.

\section{Perawatan Preventive pada Air System}

Meski memiliki fungsi yang sangat vital, kadang perawatan preventive pada air system kurang diperhatikan. Kurangnya perhatian terhadap komponen - komponen air system ini tentu saja dapat menimbulkan masalah terhadap kinerja dari air system itu sendiri, salah satunya akan berakibat pendeknya usia pakai komponen dari standar yang telah ditetapkan oleh factory. Oleh karena itu perawatan preventive yang dilakukan secara teratur akan mengoptimalkan umur komponen dan performa dari air system itu sendiri. Langkah - langkah perawatan yang utama antara lain :

- Lakukan pembuangan tekanan angin pada valve drain yang terdapat pada kedua air tank (satu berada di atas hydraulic tank dan satunya lagi berada di sebelah kanan kabin operator) pada setiap akhir shift (sesuai dengan anjuran OMM) untuk membuang uap air yang tersimpan di tanki akibat kondensasi.

- Lakukan walk around inspection pada unit sebelum / setelah mengoperasikan unit untuk memastikan apakah ada kebocoran pada komponen.

- Lakukan pemeriksaan rutin pada setiap 250 jam pada air dryer untuk mengetahui kondisi catridge air dryer.

- Lakukan penggantian catridge air dryer setiap melakukan service 2000 jam.

\section{KESIMPULAN}

Kesimpulan berdasarkan hasil penelitian dan pembahasan adalah sebagai berikut :

1. Analisa penyebab kerusakan pada air system OHT 777D adalah kontaminasi, kegagalan pada air dryer, uap air yang terkondensasi sehingga komponen air system tidak bekerja secara sewajarnya.

2. Kerusakan komponen air system yang terjadi di site 017C Malinau PT. Arkananta Apta Pratista dapat dimimalisir dengan cara melakukan perawatan preventive sesuai anjuran OMM (Operation and Maintenance Manual) pada setiap unit 777D.

Sedangkan beberapa saran yang dapat diberikan adalah sebagai berikut :

Air system merupakan salah satu sistem yang tidak boleh diabaikan. Oleh karena itu seharusnya perawatan pada air system harus dijalankan agar sistem berfungsi dengan optimal. Pembuangan tekanan udara pada kedua air tank melalui drain valve harus dilaksanakan setiap akhir shift agar dapat mengurangi terjadinya terkondensasinya uap air pada air tank sehingga dapat meminimalisir cost dan mengurangi terjadinya breakdown unit yang tidak direncanakan (unscheduled). Gunakan kacamata pelindung pada saat membuang tekanan udara dan melakukan pekerjaan memasang atau memperbaiki komponen untuk menghindari simburan udara bertekanan mengenai mata. Menjalankan schedule maintenance sesuai dengan OMM (Schedule pengecekan kondisi air dryer setiap 250 jam dan penggantian Catridge Air Dryer setiap 2000 jam.

\section{UCAPAN TERIMA KASIH}

Terima kasih diucapkan kepada pihak Manajemen PT. Arkananta Apta Pratista Site Malinau atas segala keterbukaan data dan informasinya untuk memberikan pengembagan keilmuan di bidang alat berat. 


\section{DAFTAR PUSTAKA}

[1] OHT 777D, “Analisa Data WO (Work Order) dan DMBD (Daily Mean Breakdown)., PT. Arkananta Apta Pratista Site Malinau, 2019

[2] Tomaszewski F., Tomaszewski S, "Optimization of the design of relay valves for rail vehicles braking systems in the context of train traffic safety," MATEC Web of Conferences, 294, 03013, 2019.

[3] J. Merkisz, L. Rymaniak, "Eksploatacja I Niezawodnosc-Maintenance and Reliability," Volume: 19, Issue: 4, Pages: 522- 529, 2017. DOI: 10.17531/ein.2017.4.5,

[4] Tomaszewski F., Tomaszewski S.: Rail Vehicles, Volume: 4, Pages: 1-10, Published: 2015

[5] Rasma1, H. Basri, “Analisa Service Brake Malfunction pada Unit Dump Truck (HD) 1500-7," Seminar Nasional Sains dan Teknologi, Fakultas Teknik Universitas Muhammadiyah Jakarta, Oktober 2019

[6] Nuri, R. Anjas and S. Putro, "Analisa Kerusakan Braking System Pada XCMG Wheel Loader ZL50GN (Study Kasus di PT. GM Tractor,” Skripsi thesis, Universitas Muhammadiyah Surakarta, 2020.

[7] 777D System Operation," Spesifikasi Alat Berat [Online], https://penambang.com/spesifikasi-777d, diakses tanggal 19 Juli 2019.

[8] 777D System Operation, "Topik 5 Sistem udara dan rem Caterpillar [online] http://ondyx.blogspot.com/2014/01/pengertian-dan-fungsi-pneumatik.html?m=1, diakses tanggal 20 Maret 2020.

[8] Training Center PT. Trakindo Utama, "Intermediate Power Train System, Cileungsi, Bogor, 2008

[9] Cat.com, "Product Equipment Off Highway Truck," [online] https://www.cat.com/en ID/products/new/equipment/off-highway-trucks/off-highway-trucks/1000027608.html

[10] 777D System Operation," Spesifikasi Alat Berat [Online], https://penambang.com/spesifikasi-777d, diakses tanggal 19 Juli 2019. 